\title{
UM DIREITO DE CLÁUSULAS GERAIS? SENTIDO E LIMITES
}

José de Oliveira Ascensão*

\section{ENQUADRAMENTO DO TEMA}

O tema que nos propomos versar, para ser devidamente enquadrado, exige que partamos de um pouco longe.

Há que ter como pano de fundo a Revolução Francesa, que encerra toda uma época histórica e abre, de modo assaz sanguinolento, as portas para a Idade Contemporânea, que vivemos ainda.

Numa outra vertente, a um Direito que até então teria como fundamento a Justiça, sucede o Direito abstrato, único e imutável, criado pela Razão humana. Mas esse Direito ideal poderia ser reduzido a escrito e posto a vigorar como lei. O modelo é o Code Civil de Napoleão, que se apresenta como o jusracionalismo codificado e é (im)posto a vigorar em vários países europeus.

Os juízes são objeto de suspeita, por serem considerados braços do poder que fora derribado. Exalta-se pelo contrário a lei, divinizada como produto da Razão universal e simultaneamente expressão da vontade do povo. Assim, o juiz é apenas a boca que "fala" as palavras da lei - dentro do entendimento simplista de que a lei continha todas as soluções. Temos o que chamamos o mecanicismo ${ }^{1}$ - o juiz, quando solicitado, ditava como que automaticamente a solução legal.

O papel do juiz é ainda ulteriormente limitado pelo júri, que é também uma instituição ideológica, imposta por se considerar que exprimia a soberania do povo.

Professor catedrático da Faculdade de Direito de Lisboa. Advogado.

1 Veja-se o nosso Mecanicismo, equidade e cláusulas gerais no Direito das Obrigações, in "Direito das Obrigações - Reflexões no Direito Material e Processual", obra em homenagem a Jones Figueirêdo Alves (coordenadores: Fernanda Pessoa Chuahy de Paula et al.), Ed. Gen/Método (São Paulo), 2012, 327-338. 
Esta visão está na base da sociedade liberal do séc. XIX, embora pela via de muitas metamorfoses e convulsões. Traz a marca do subjetivismo, muito próprio do individualismo que se tornou dominante com a revolução industrial; e com o voluntarismo, que justificará as vinculações assumidas: o contrato obriga porque foi querido, fosse qual fosse o seu conteúdo.

É caraterística deste quadro a emergência do contrato de adesão. É uma figura de caraterização e avaliação difíceis. Não é um novo tipo de contrato, será antes uma matriz de contratos. O conteúdo era predisposto por uma das partes (evidentemente, a parte mais forte) e oferecido a quem estivesse em condições de se vincular. A diferença de poder efetivo das partes é irrelevante: bastava que alguém "aceitasse". Mas teria querido? Dispensaram-se indagações mais profundas. Bastava que o aderente conhecesse (ou tivesse podido conhecer) aquilo a que se vinculava.

Apesar de suscitar também contestações, pelo emergir dos choques sociais e pela formulação de doutrinas coletivistas, o sistema foi imposto por quem dele tirava proveito.

No tocante à Ciência do Direito, a prioridade passa para a doutrina alemã ${ }^{2}$. Mas podemos dizer que a tendência geral foi a de um refúgio no que podemos designar o formalismo.

No início do séc. XIX a figura dominante foi a de Savigny. As suas construções histórico-sistemáticas são brilhantes, mas não privilegiam a apreciação do conteúdo das situações jurídicas. Na segunda metade do séc. temos o positivismo jurídico, mas ao contrário do que se poderia esperar este caraterizou-se no Direito pelo refinamento da técnica, com o isolamento do fenômeno jurídico em relação à realidade social.

Entre Savigny e o positivismo, temos Jhering. Este desperta-nos para a substância, com livros como O Fim do Direito e A Luta pelo Direito. Mas dele podemos dizer que teve razão antes de tempo. As suas posições só vieram a dar pleno fruto após a guerra de 1914-18, a Grande Guerra.

Em 1900 surge o Código Civil alemão, o BGB ${ }^{3}$. A ele está ligado o nome de outro notável jurista, Windscheid. A linha técnica é brilhante e ganha o primeiro plano na atenção dos estudiosos, mas a sensibilidade para a substância é escassa.

Com tudo isto temos as bases da Belle Époque, a satisfação das camadas burguesas e a tranquilidade da prosperidade assegurada.

2 É também importante a evolução no Reino Unido, mas podemos abstrair dela pelo afastamento dos sistemas de common law em relação aos do continente europeu.

3 Bürgerliches Gesetzbuch. 
Mas tudo desaba com a chamada Grande Guerra. Os escombros que deixou englobaram também os escombros da Ciência Jurídica. Tudo ficou para rever a uma nova luz.

Há aspetos positivos, como a reação pós-guerra na Alemanha, a grande vencida, e a sensibilidade social despertada. Surge então a Constituição de Weimar e a proclamação da função social - "A propriedade obriga". A nova orientação teve também como base a consciencialização da pessoa humana, que aparece como um "upgrade" do indivíduo, que dominara no séc. XIX. Aperfeiçoam-se institutos como as cláusulas negociais gerais ${ }^{4}$, que exprimem esta nova atenção prestada à substância dos regimes jurídicos ${ }^{5}$.

Infelizmente, o que poderia ser um movimento promissor é abruptamente truncado pela emergência do nazismo, a guerra mundial de 39-45, as duas bombas atómicas lançadas sobre cidades densamente povoadas e a subsequente divisão do mundo em dois grandes blocos hostis. Por sorte nossa, ficamos do lado de cá.

\section{A CLÁUSULA GERAL E 0 LUGAR CENTRAL DO JUIZ NA SUA APLICAÇÃO}

Feito este enquadramento entramos agora (dirão que já não era sem tempo...) no tema das cláusulas gerais.

O problema imediato consistia em saber como resolver com leis antigas os magnos problemas jurídicos suscitados. Desde um Código Civil de 1804 em França aos códigos subsequentes, tudo aparecia desatualizado perante a magnitude dos problemas a resolver.

A grande tentação é a do recurso à equidade. Tudo se resolveria pela busca da solução justa à luz das circunstâncias do caso concreto. Mas utilizar a equidade sem haver lei que o permita é recorrer a um expediente ilícito, pura e simplesmente ${ }^{6}$. munidade.

O problema era outro. Era o de reestruturar a ordem objetiva da co-

Não obstante, algum progresso tinha sido feito. Em 1942 fora aprovado o Código Civil italiano, instrumento científico de muito mérito, apesar da

4 Designação que substitui o contrato de adesão e que preferimos a "condições gerais dos contratos" e a "cláusulas contratuais gerais".

5 No ponto de vista político-sociológico, aprofunda-se a cisão entre social-democracia e comunismo (sem nos deixarmos prender pelos rótulos).

6 Isto não impede que toda a aplicação da lei se deva fazer à luz das circunstâncias do caso concreto. Mas aqui o que funciona não é a equidade, porque o critério de decisão não é já a Justiça, como valor, mas a máxima de decisão aplicável àquele caso, extraída do ordenamento normativo. 
época em que foi elaborado. As constituições que foram sendo aprovadas terminada a guerra davam relevo aos direitos fundamentais. E sobretudo, manifestavam respeito pelo primado da pessoa humana, que surgia por contraste com as ocorrências que tinham levado à catástrofe, nomeadamente na Europa.

As cláusulas gerais surgem-nos justamente como um dos marcos deste Direito valorativo a que se tende. Mas antes de passar ao exame destas, advertimos que a terminologia adotada é extremamente infeliz.

"Cláusula" é uma estipulação negocial, no seu sentido básico. Aparece com este sentido quando falamos em "cláusulas negociais gerais", por exemplo. Mas as cláusulas gerais que referimos agora não são estipulações das partes, são polos ou critérios normativos de valoração, que presidem à interpretação e aplicação de regras jurídicas. São elementos que injetam sentido e substância na ordem normativa, de modo a enriquecê-la, para se tornar uma ordem valorativa mesmo quando não há mudança de leis. Podemos dizer que constituem ainda preceitos, mas não são regras ${ }^{7}$, como as outras, e muito menos cláusulas. Não pautam um tipo de relação, antes presidem à interpretação e sobretudo à aplicação de regras jurídicas, introduzindo sentido e substância na aplicação. Exigem por isso uma valoração por parte do intérprete, não se bastando com meras descrições.

A cláusula geral mais utilizada é a da boa-fé ${ }^{8}$. Mas há que prevenir contra o abuso desmesurado que desta cláusula se tem feito, porque o que serve para tudo não serve para nada.

$\mathrm{O}$ ato de valorar é exclusivamente humano: precisa pois de um medium. O medium é, em última análise, o juiz. Este passa assim a ter uma função radicalmente inversa da que lhe foi atribuída inicialmente, como uma espécie de autômato na indicação e aplicação da lei. Ganha um novo protagonismo, um lugar central, particularmente na aplicação desses critérios à solução dos casos concretos.

\section{A VIRAGEM PARA A ETICIZAÇÃO DO DIREITO}

O juiz será capaz de desempenhar um papel tão responsabilizador?

Não é assim que se coloca a questão. O juiz tem de o fazer. Cabe-lhe resolver todas as matérias sujeitas a juízo, das da energia nuclear às psiquiátricas... E tem de aplicar as cláusulas gerais por maioria de razão, uma vez

7 As regras ou normas são estruturadas por uma previsão e uma estatuição.

8 Prevê-a por exemplo o art. 422 do CC de 2002. Dispõe: “Os contraentes são obrigados a guardar, assim na conclusão do contrato, como na sua execução, os princípios de probidade e boafé". 
que suscitam questões de índole estritamente normativa, mesmo quando têm um fundo ético (probidade, bons costumes...).

Mas as cláusulas gerais são muitas. Além das que acabamos de referir, temos a ordem pública, a confiança, a proporcionalidade, a razoabilidade e muitas mais.

O labor da doutrina e da jurisprudência tem construído outras, como o abuso do direito, o venire contra factum proprium, o tu quoque...

Como o juiz tem de saber valorar, uma vez que se encontra no centro de um direito de cláusulas gerais, exige-se-lhe muita formação - tal como se lhe exige bom senso e sentido dos limites.

Mas, como dissemos, nunca o juiz pode dispensar a lei, antes a pressupõe e cabe-lhe captá-la, bem como aplicá-la e até colaborar na melhoria desta.

No início deste século vivemos um momento jurídico alto, com a Reforma do Livro do Direito das Obrigações do BGB. Falou-se modestamente na Modernisierung, mas na realidade foi-se além.

Foi obra de anos de estudos e debates e ficou a cargo de uma equipa de grande nível, presidida pelo Prof. Canaris - o que bastaria para o fazer passar à História. Com efeito, reformar um monumento científico como o BGB é uma grande tarefa, que foi coerentemente levada a cabo.

Teve desde logo um impacto profundo no modo de conceber a legiferação.

Na verdade, após quase dois séculos de codificação, a moda tinha passado a ser a descodificação. Esta corrente teve reflexos no Brasil, num movimento que considerava a codificação ultrapassada e defendia a descodificação como a prática adequada ao dinamismo da sociedade atual.

A reforma do Livro do Direito das Obrigações do BGB veio demonstrar que era possível a recodificação, passando esta a ser o movimento de vanguarda. As vantagens são evidentes: permitem que sejam reintegradas no Código Civil matérias que andavam dispersas por leis extravagantes. A recodificação dava-lhes coerência, pois submetia-as a uma unidade de sentido, com base em princípios comuns. E permitia robustecer o conteúdo sóciofuncional do BGB, dando abertura a princípios arrojados que o enriqueciam.

Mas para o conseguir, são necessários juristas de nível elevado. Por isso é tão importante a formação jurídica.

A tendência "substancialista" manifesta-se logo no primeiro artigo do Livro do Direito das Obrigações, o § 241. A este é acrescentado um n.․ㅡ 2, que 
podemos traduzir assim: "A obrigação pode, pelo seu conteúdo, obrigar cada parte a ter em conta os direitos, bens jurídicos e interesses da outra parte". Há assim uma consagração geral da solidariedade nas obrigações, que vem na continuidade dos "deveres de proteção" que a doutrina alemã aprofundara criteriosamente ${ }^{9}$.

Resulta daqui uma visão humanizada da obrigação. Esta visão põe em causa a própria definição corrente da relação jurídica, como "a solução pacífica dum conflito de interesses". Não seria a intenção de quem a utilizava, mas $\mathrm{o}$ acento no conflito fazia ressaltar o antagonismo. A mudança operada tem o efeito nada despiciendo de antepor outra vertente, a da cooperação ou colaboração. A obrigação é um instrumento em que as partes se implicam para uma tarefa e um fim comuns, que satisfaz os interesses de ambas ${ }^{10}$. Assim se dá um passo muito importante na eticização do Direito e portanto na superação do formalismo inicial.

Integra-se nesta tendência a insistência na função das situações jurídicas. Particularmente no que respeita à função social, a Constituição Federal de 1988 é provavelmente, entre todas as constituições, a que lhe dá maior relevo ${ }^{11}$.

Esse relevo projeta-se no Código de Defesa do Consumidor de 1990. Mas o que respeita ao Direito do Consumidor merece uma consideração autônoma.

\section{DIREITO DO CONSUMIDOR E DIREITO CIVIL}

O Código de Defesa do Consumidor é, ao que saibamos, o primeiro Código do Consumidor do mundo.

Surgido apenas dois anos após a Constituição, teve um objetivo estratégico que ultrapassa muito a própria defesa do consumidor. Foi o instrumento a que coube a função de implantar no Direito Privado os princípios ou pelo menos o espírito da Constituição. Funciona a chamada aplicação horizon-

9 No Projeto afirmava-se na sequência: "Este pode ser o único conteúdo da obrigação". Este trecho acabou porém por ser eliminado.

${ }^{10}$ Embora estes continuem a poder ser diferentes. Neste caso, que é o mais frequente, a cooperação é instrumental para a obtenção dos fins de ambas as partes.

11 Podemos recordar outra figura que só se explica tendo em consideração o plano funcional das situações jurídicas: o chamado abuso do direito. A figura é originária da doutrina francesa e a expressão é de grande infelicidade. No Código Civil atual está incluída nos atos ilícitos. O art. 187, retomando uma fórmula que vem do Código Civil grego, com passagem pelo Código Civil português, dispõe que "comete ato ilícito o titular de um direito que, ao exercê-lo, exceda manifestamente os limites impostos pelo seu fim econômico ou social, pela boa-fé ou pelos bons costumes". Na realidade, o que está em causa é o exercício disfuncional de situações jurídicas. É mais uma vez a ideia de função a irromper da lei. 
tal dos princípios constitucionais, o que conduz a uma mudança no entendimento global das instituições privadas. O fato é particularmente importante no Brasil, pois vigorava o Código Civil de 1916 que, apesar da sua qualidade, era ainda uma emanação do positivismo dominante. O Código do Consumidor permitiu uma aplicação integrada de princípios constitucionais; e particularmente, a atribuição às instituições privadas do sentido funcional que a Constituição reclama.

Mas surgiam dificuldades de ajustamento. Estava suspenso o Projeto de um novo Código Civil, fruto do labor de um lote qualificado de juristas, sob a orientação de Miguel Reale ${ }^{12}$. Mas esse Projeto remontava ao início dos anos 70. Procedeu-se a uma revisão e mais uma vez se verificou que as assembleias legislativas não são as entidades adequadas para providenciar códigos: a revisão foi limitada e insuficiente. O Código Civil, finalmente aprovado em 2002, estava muito longe de espelhar as orientações da Constituição de 1988.

Isto significa que, no Brasil, o Direito Privado assenta pelo menos num tripé algo desconjuntado: o Código Civil de 2002, que deveria selar a evolução, é na substância anterior à Constituição de 88 e em várias matérias está em conflito com o Código do Consumidor de 90 . O jurista tem de recorrer a todas estas fontes e proceder à operação delicada de extrair desta pluralidade a norma aplicável. E assim, por exemplo, o espírito de cooperação das partes no negócio, de que falamos atrás, pode também ser prosseguido no Brasil.

Fala-se por isso, noutra importação, em Diálogo das Fontes. É uma imagem, sem dúvida interessante, mas é uma imagem só. Tecnicamente, o que há na essência é outro princípio fundamental: o princípio da unidade da ordem jurídica. É este que permite à jurisprudência e à doutrina elevar-se progressivamente a consequências não expressas, mas assentes nas fontes aplicáveis.

No domínio das cláusulas gerais, este princípio permite que todo o Detrito participe das cláusulas gerais constitucionais, ainda que estas tenham sido originadas ou desenvolvidas só no nível constitucional. É o que se passa, paradigmaticamente, com a proporcionalidade. Hoje reconhece-se que esta se projeta em toda a ordem jurídica, embora a sua gênese tenha sido estritamente constitucional. É a projeção de valores que não podem deixar de compor todos os ramos do Direito ${ }^{13}$.

${ }^{12}$ E com a participação dinamizadora do depois ministro Moreira Alves.

${ }^{13}$ De certo modo, assim se passa também com o princípio afim da razoabilidade. 


\section{VALORAÇÃO, SUBJETIVISMO E ARBÍTRIO}

Toda a afirmação suscita o seu contrário. A emergência de um Direito valorativo e funcionalizado não deixa de ter os seus perigos também. O perigo maior é o de se resvalar para o arbítrio, particularmente para o arbítrio do julgador.

É frequente no Brasil afirmar-se, quando se refere uma realidade valorativa: "Isso é subjetivo". Com subjetivo quer-se então significar que está sujeito ao entendimento de cada um. Não está. Na base dos valores ou princípios estão grandes realidades intelectuais que têm o seu conteúdo próprio. Há que determiná-lo, mesmo que exijam um esforço de abstração grande e provoquem divergências. Todo o raciocínio é, por natureza, sempre subjetivo, mas o que se pretende com aquele qualificativo usual é antes um subterfúgio para fugir à tarefa intelectual da busca do sentido. Deste modo, tudo se lança para o arbítrio - no final, para o arbítrio do julgador. O juiz decidiria como gostasse mais, com lei ou sem lei.

Não pode ser assim. O arbítrio judicial é incompatível com o estádio civilizacional em que nos encontramos. A ordem jurídica exige estabilidade e previsibilidade das soluções. São estas que garantem a segurança que proporciona uma ordem jurídica objetiva de que todos participam. A invocação da subjetividade pode disfarçar simplesmente a ignorância ou a preguiça do intérprete.

Pode-se chegar a extremos, como acontece com a corrente, também importada, que se designa Direito Alternativo ${ }^{14}$. Esta implica a imposição aos demais de uma visão do mundo. Quando vemos um dos seus próceres afirmar que, para se ser bom alternativista, é necessário ser-se marxista, exprimese uma posição inadmissível numa sociedade pluralista como a nossa, fazendo depender o Direito de uma ideologia. Isto significa a degradação da sociedade pluralista em que nos situamos e que com prática unanimidade se afirma prosseguir, pela leitura do Direito objetivo como um direito sectário.

Mas há um perigo ainda maior, consistente no manuseio acrítico das cláusulas gerais. Cada cláusula tem um sentido, que é necessário fixar com precisão. Mas não é isso que frequentemente vemos acontecer.

Tomemos como exemplo a boa-fé. Pode-se, sem exagero, considerá-la a rainha das cláusulas gerais. Mas assistimos ao fenômeno preocupante de a todo o propósito invocar a boa-fé. Por exemplo, quando se defrontam os problemas da validade de cláusulas do contrato de adesão, ou de cláusulas

\footnotetext{
${ }^{14}$ Veja-se a nossa Introdução à Ciência do Direito, 3. ${ }^{\mathrm{a}}$ ed., Renovar (Rio de Janeiro), 2005, n. ${ }^{\text {os }} 275$ a 277. Veja-se também o nosso estudo Derecho Alternativo, in Derecho Penal Contemporáneo Revista Internacional, Legis (Bogotá - Colombia), n.․ 10, Enero-Marzo 2005, 75-86.
} 
ilícitas em geral, ou das cláusulas não comunicadas, logo se afirma que são rejeitadas por contrárias à boa-fé. Mas na realidade são ilícitas por o serem, pura e simplesmente, sem para nada ser necessário invocar a cláusula geral da boa-fé.

Deste modo, a boa-fé acaba por ser uma bengala que serve para tudo. Mas diz-nos a experiência que o que serve para tudo não serve para nada. A cláusula geral fica assim dessorada. Em vez de se procurar o seu sentido autêntico transformou-se num estribilho sem valor argumentativo.

Outro desvio que devemos assinalar está no uso inadequado das cláusulas gerais nas próprias leis. Vamos dar um exemplo extraído da lei portuguesa, numa matéria que é aliás muito sensível também no Brasil: a das limitações voluntárias dos direitos de personalidade ${ }^{15}$.

$\mathrm{O}$ art. 81 do Código Civil português, regulando a matéria, determina que toda a limitação voluntária é nula, se for contrária aos princípios da ordem pública.

Se não erramos, a cláusula apropriada não é esta: é antes a dos bons costumes. O exemplo é porém elucidativo da necessidade de se aprofundar o sentido próprio de cada cláusula geral, sob pena de se criarem grandes dificuldades à prática. No caso, a cláusula da ordem pública é de conteúdo particularmente difícil de fixar. O intérprete defrontará grandes perplexidades na aplicação, se não se tiver esclarecido antecipadamente o sentido de cada cláusula.

Por vezes ainda, foge-se a este indispensável trabalho através de um subterfúgio: acumulam-se cláusulas gerais, como se todas elas fossem aplicáveis ao caso concreto. $\mathrm{O}$ mau exemplo provém por vezes do próprio legislador. Seja o caso do art. 51 IV do Código do Consumidor, a propósito das cláusulas abusivas: dispõe que são nulas de pleno direito as cláusulas que "estabeleçam obrigações consideradas iníquas, abusivas, que coloquem o consumidor em desvantagem exagerada, ou sejam incompatíveis com a boafé ou a equidade". Mas não é a repetição de cláusulas que dispensa o trabalho de caraterização de cada; e, em caso da legiferação, que torna preciso o sentido. Pelo contrário, o intérprete ver-se-á perante a dificuldade da escolha da cláusula adequada e até perante repetições eventuais: é assim que terá de conjugar "iníquas" com incompatíveis com a equidade, quando significam praticamente a mesma coisa.

${ }^{15}$ No Brasil, o art. 11 do Código Civil dispõe que os direitos de personalidade não podem sofrer limitação voluntária - o que cria grandes problemas porque a determinação é completamente irrealista. A todo o momento nós restringimos validamente os nossos direitos fundamentais, na normalidade ética da vida corrente. Nenhuma sociedade poderia funcionar de outra maneira. 


\section{0 CONTRIBUTO DAS CLÁUSULAS GERAIS}

O caminho correto é exatamente o contrário. Consiste antes em procurar o sentido específico de cada cláusula geral. Cada uma exige um trabalho específico de reflexão, mas só deste modo se poderá chegar a uma aplicação justificada e segura. Assim procedem os juristas dos países que exemplarmente trabalham com elas: racionalizam-nas, de modo a que se extraia todo o sentido e potencial de cada cláusula, para chegar pela aplicação dela a novos resultados jurídicos.

A jurisprudência tem aqui uma participação essencial, ao determinar a solução dos casos concretos pela escolha e aplicação das cláusulas adequadas, em diálogo com a doutrina.

Deste modo, as cláusulas gerais surgem como grandes propulsoras do desenvolvimento da ordem jurídica, dando pistas de descoberta ou desenvolvimento da ordem normativa; e levam até, pela consolidação dos resultados obtidos, à gênese de outros preceitos legais ${ }^{16}$.

As cláusulas gerais são ainda valiosas encaradas por outro ângulo.

Se bem utilizadas, elas representam elementos de aticização e humanização da ordem jurídica.

Falamos atrás do espírito de cooperação que a visão social dos ordenamentos constitucionais impõe.

As leis civis não os traduzem por vezes adequadamente. Mas a introdução de cláusulas gerais, com a densidade substantiva que as carateriza, exclui os entendimentos meramente formais.

Suponhamos que, em contrato de compra e venda de coisa móvel, se estipulou que ao vendedor cabia a entrega, devendo deixar a coisa vendida à porta da casa do comprador.

Suponhamos que o vendedor vem fazer a entrega em dia de temporal e não se encontra ninguém em casa.

O vendedor resolve então deixar a mercadoria à porta da casa. Com isso a embalagem é arrastada pela enxurrada e a mercadoria perde-se.

O vendedor, formalmente, cumpriu: deixou como foi estipulado.

Mas, num ponto de vista substancial, ele não cumpriu o que lhe competia para com o devedor. Substancialmente, há um laço de cooperação de-

\footnotetext{
${ }^{16}$ Como aconteceu exuberantemente na "modernização" do livro do Direito das Obrigações na Alemanha, que conduziu à incorporação do BGB de muitas soluções consolidadas já pela doutrina e consagradas por jurisprudência constante.
} 
vedor/ /credor, que não é compatível com o desinteresse do vendedor pela sorte da mercadoria.

Ao vendedor cabe ainda providenciar para que o interesse da outra parte seja efetivamente satisfeito. Isso só acontece se ele agir de maneira que a mercadoria fique em condições de chegar íntegra ao comprador, por exemplo, deixando-a em lugar seguro no exterior da casa ou levando-a consigo para entrega posterior.

Dir-se-á: mas isso pode acarretar trabalhos e despesas ao vendedor que não estavam previstos.

É verdade. Mas também leva a considerar que, numa relação correta de cooperação, tudo o que as partes fizerem, se corretamente tiveram por fim preservar os interesses da outra parte, deve ser ressarcido.

Isto quer dizer que a conduta das partes deve ser objeto duma apreciação substancial, à luz do fim do contrato e dos interesses envolvidos, não bastando a satisfação meramente formal que corresponderia afinal a hipocrisia.

Assim as cláusulas gerais, que traduzem o sentido ético e funcional para que tende o ordenamento hoje emergente, contribuem muito para a humanização do Direito, que surge como proposta de vanguarda nas nossas ordens jurídicas. 